\title{
HEALTH POLICY Insurance Transitions and Changes in Physician
and Emergency Department Utilization: An Observational
Study
}

Michael L. Barnett, MD, $M S^{1,2}$, Zirui Song, $M D$, $P h D^{3,4}$, Sherri Rose, $P h D^{3}$, Asaf Bitton, $M D, M P H^{2,3,5}$, Michael E. Chernew, $P h D^{3}$, and Bruce E. Landon, MD, MBA, MSc $c^{3,6}$

${ }^{1}$ Department of Health Policy and Management, Harvard T.H. Chan School of Public Health, Boston, MA, USA; ${ }^{2}$ Division of General Internal Medicine and Primary Care, Department of Medicine, Brigham and Women's Hospital, Boston, MA, USA; ${ }^{3}$ Department of Health Care Policy, Harvard Medical School, Boston, MA, USA; ${ }^{4}$ Department of Medicine, Massachusetts General Hospital, Boston, MA, USA; ${ }^{5}$ Ariadne Labs, Brigham and Women's Hospital \& Harvard T.H. Chan School of Public Health, Boston, MA, USA; 'Division of General Medicine and Primary Care, Beth Israel Deaconess Medical Center, Boston, MA, USA.

BACKGROUND: Shopping for health insurance is encouraged as a way to find the most affordable coverage that best meets an enrollee's needs. However, the extent to which individuals switch insurance and subsequent changes in health care utilization that might arise, particularly new physician visits, are not well understood.

OBJECTIVE: To examine the relationship between insurance switching and new physician and emergency department visits around the time of a switch.

DESIGN: Observational study using a difference-indifferences design to compare those switching insurance carriers with propensity score-matched controls who did not switch, stratified based on whether individuals initially had private or Medicaid insurance coverage. All analyses adjusted for individual and insurance characteristics. PARTICIPANTS: Continuously insured, non-elderly individuals with private or Medicaid insurance coverage in Massachusetts from 2010 to 2013.

MAIN MEASURES: Rates of new primary care and specialist physician visits, as well as rates of emergency department visits.

KEY RESULTS: Before matching, among 1,628,057 continuously insured individuals, 418,231 (26\%) switched insurance carriers during a 2 -year period. Characteristics of switchers and non-switchers were similar after matching ( $n=316,343$ in each group). After matching, switching plans was associated with a $203 \%$ and $47.5 \%$ increase in the rate of new primary care physician visits following switching for those initially with Medicaid or private coverage, respectively (both $p<0.001$ ), with a large shortterm increase, diminishing over time. Among those with Medicaid coverage, switching was associated with a $14.9 \%$ higher rate of ED visits during the month of switching $(p<0.001)$, but otherwise decreased modestly after switching.

CONCLUSIONS: Insurance switching is common, and is associated with increased new physician visits and temporarily increased ED use among the publicly insured. As

Electronic supplementary material The online version of this article (doi:10.1007/s11606-017-4072-4) contains supplementary material, which is available to authorized users.

Received November 13, 2016

Revised March 30, 2017

Accepted April 19, 2017

Published online May 18, 2017 insurance markets become more volatile in the current policy environment, understanding changes in utilization after insurance switching may become increasingly important.

KEY WORDS: health insurance; primary care utilization; emergency department utilization; insurance exchanges.

$\mathrm{J}$ Gen Intern Med 32(10): 1146-55

DOI: $10.1007 / \mathrm{s} 11606-017-4072-4$

(C) Society of General Internal Medicine 2017

\section{INTRODUCTION}

By establishing insurance exchanges to promote competition among private plans and providing premium subsidies for those with incomes up to $400 \%$ of poverty level, the Affordable Care Act (ACA) enabled an estimated 12.7 millions Americans to obtain insurance by shopping on an exchange. ${ }^{1}$ Yet while shopping for insurance is generally viewed in a positive light - allowing consumer preference and price competition to play a larger role in individual decisions on health insurance - the implications of switching insurance for health care use remain poorly understood.

Insurance enrollment is a dynamic process. For example, on the exchanges, individuals can change plans during the annual open enrollment process, and thus changes in premiums, coverage generosity, and individual health status may lead individuals to switch plans each year. While competition is thought to result in lower prices and improved quality of care $^{2-7}$ it is also likely to lead to increased rates of switching among private plans as well as among private insurers participating in Medicaid as enrollees choose among plans. ${ }^{3,8}$

The implications of plan switching with respect to health care use and the stability of patient-physician relationships may be a meaningful consideration in this environment. Because providers are not consistently included in all insurance networks, such switching could compel patients to change physicians to avoid significant out-of-pocket expenses, which could interrupt clinical relationships and create additional costs in time and effort for both patients and physicians. ${ }^{9}$ Prior evidence shows that individuals switching insurance carriers 
are more likely to have changes in their usual source of care, 10, 11 a problem that may be exacerbated as narrow networks become more common. ${ }^{12}$ Since prior research has focused on the transition from no insurance to insurance coverage, 2,13 there is little evidence addressing changes in health care utilization for people who switch health insurance carriers when there are no disruptions in coverage.

We analyzed data from the Massachusetts All-Payer Claims Database (APCD) on all individuals enrolled in commercial and Medicaid insurance from 2010 through 2013, to examine the association between insurance switching and subsequent health care utilization around the time of a switch, focusing on visits to new primary care and specialist physicians and the emergency department. Because insurance switching might be a consequence of a desire to switch providers or development of a new health condition, we conducted a number of sensitivity analyses to assess the contribution of these factors to our results.

\section{METHODS}

\section{Data Source and Study Population}

The Massachusetts APCD contains detailed data on health care utilization, insurance eligibility, and provider credentialing across all commercial payers and public health insurance programs in Massachusetts, representing approximately $90 \%$ of the state's non-elderly population. ${ }^{14}$ 15 The APCD uses individual identifiers from insurers to create a probabilitybased "master patient identifier" that can be used to follow enrollees when they change insurers (see online Appendix). ${ }^{16}$

Our study cohort included all Massachusetts residents aged 21-64 years as of December 31, 2013, who had at least 3 calendar years of continuous enrollment with any APCDparticipating insurance provider during the 4-year period from 2010 to 2013, based on their master patient identifier. We chose a 3-year period of continuous enrollment to ensure 12 months before and after an insurance switch for our study design, and additionally used the prior-calendar-year claims for risk adjustment. We defined continuous enrollment as $\geq 11$ months of insurance coverage in a year. We excluded any individual covered by Medicare during this period, as Medicare claims are not included in the APCD.

This project was approved by the Committee on Human Subjects at Harvard Medical School.

\section{Identifying Insurance Carrier Switching}

Our primary exposure was switching insurance carriers, which we defined when an individual ("switcher") began enrollment with a new health insurance carrier (i.e., not changing plans within an insurance carrier). Because identifiers for individual plans in the APCD were not consistent within carriers, we were unable to examine switches between plans within a carrier. For each person, we defined an index insurance carrier (e.g., Aetna or United) based on their health insurance enrollment in
January 2011. We assigned the date of a switch to the month of the first instance when a person began enrollment with a new carrier, even if their prior enrollment extended beyond this month, because we found that plans did not always accurately record when coverage ended (see online Appendix for details). We defined "Medicaid" coverage as enrollment in MassHealth or in a privately contracted MassHealth health plan. We studied switchers who changed insurance during calendar years 20112012, including January 1, 2013, because January 1 is a common date for insurance switching.

\section{Outcomes}

We defined new visits to primary care and specialist officebased physicians based on evaluation and management (E\&M) Current Procedural Terminology (CPT) codes (see online Appendix for list of codes used) for new visits. A new visit CPT code can only be used if a patient has not been seen by any physician within that practice within the previous 3 years. ${ }^{17}$ Because payers in the APCD do not consistently use a single physician identifier such as the national provider identifier (NPI), we created a master physician crosswalk between NPI and insurer-specific identifiers and used this to define specialty (see online Appendix for details). We defined emergency department (ED) visits by any claim with an emergency care-associated E\&M code (99281-99285, 99291, 99292) or an ED-associated revenue center code (04500459,0981 ) in hospital claims. ${ }^{18,19}$

\section{Covariates}

To measure comorbidities, we calculated hierarchical condition category (HCC) scores using software available from the Centers for Medicare and Medicaid Services. ${ }^{20}$ We assigned an HCC score from 2010 or 2011 for individuals who switched insurance in 2011 or 2012 plus January 1, 2013, respectively. To derive a proxy measure of socioeconomic status, we linked individuals' five-digit ZIP Code to the publicly available "Area Deprivation Index," a measure derived using a weighted combination of 17 census-level indicators of socioeconomic disadvantage. $^{21,22}$ We also assigned members to an initial insurance market category (private vs. Medicaid insurance). Other variables included member age as of December 31, 2010, sex, and patient identifier linkage confidence (an indicator of whether a member's identifier match was perfect or had some inference in linkage, see online Appendix). We also collected several variables related to insurance coverage for those with private insurance: plan type (e.g., preferred provider organization [PPO] vs. health maintenance organization [HMO]), employer size (ranging from individual to 500+ employees, see Table 1 for categories), and whether the employer was self-insured.

\section{Statistical Analyses}

Because individuals switching insurance may differ from those with stable enrollment, we used propensity score methods to match switchers with non-switchers without replacement in our sample using all available patient characteristics 
Table 1 Characteristics of Full and Matched Cohorts by Initial Insurance Type

\begin{tabular}{|c|c|c|c|c|c|c|c|}
\hline \multirow[b]{2}{*}{ Initial private insurance } & & \multicolumn{3}{|c|}{ Unmatched cohort* } & \multicolumn{3}{|c|}{ Matched cohort $^{\dagger}$} \\
\hline & & Non-switchers & Switchers & $p$-value & Non-switchers & Switchers & $p$-value \\
\hline & Total & $1,050,054$ & 387,702 & & 294,049 & 294,049 & \\
\hline & Age, mean (SD) & $43.4(11.2)$ & $40.7(11.6)$ & $<0.001$ & $40.1(11.4)$ & $40.9(11.6)$ & 0.003 \\
\hline \multicolumn{2}{|l|}{ HCC score, mean $(\mathrm{SD})^{*}$} & $0.33(0.43)$ & $0.32(0.42)$ & $<0.001$ & $0.32(0.47)$ & $0.32(0.41)$ & 0.431 \\
\hline \multirow[t]{2}{*}{ Sex } & Female & 52.7 & 53.3 & $<0.001$ & 53.2 & 53.3 & 0.136 \\
\hline & Male & 47.3 & 46.7 & & 46.8 & 46.7 & \\
\hline \multirow[t]{4}{*}{ Area Deprivation Index quartile ${ }^{\S}$} & 1 (least deprived) & 27.5 & 27.3 & $<0.001$ & 27.0 & 27.0 & 0.999 \\
\hline & 2 & 25.9 & 26.8 & & 26.8 & 26.8 & \\
\hline & 3 & 25.2 & 24.7 & & 24.6 & 24.6 & \\
\hline & 4 (most deprived) & 21.4 & 21.2 & & 21.6 & 21.6 & \\
\hline \multirow[t]{3}{*}{ Member ID Confidence ${ }^{\|}$} & Unable to assess & 0.9 & 0.4 & $<0.001$ & 0.4 & 0.5 & $<0.001$ \\
\hline & High & 62.9 & 63.6 & & 62.8 & 63.3 & \\
\hline & Moderate & 36.2 & 36.0 & & 36.8 & 36.3 & \\
\hline \multirow[t]{4}{*}{ Plan type } & HMO & 48.5 & 51.0 & $<0.001$ & 52.1 & 50.8 & $<0.001$ \\
\hline & PPO & 34.3 & 28.0 & & 27.6 & 27.9 & \\
\hline & POS & 10.8 & 12.0 & & 12.1 & 13.0 & \\
\hline & Other & 6.4 & 9.0 & & 8.2 & 8.3 & \\
\hline \multirow[t]{6}{*}{ Employer size } & $500+$ & 60.1 & 44.3 & $<0.001$ & 47.4 & 46.7 & $<0.001$ \\
\hline & $101-499$ & 13.7 & 15.0 & & 16.6 & 16.7 & \\
\hline & $51-100$ & 3.9 & 5.1 & & 5.9 & 5.6 & \\
\hline & $\leq 50$ & 12.5 & 13.7 & & 15.4 & 14.7 & \\
\hline & Individual & 3.8 & 4.3 & & 4.0 & 4.2 & \\
\hline & Other & 6.1 & 17.7 & & 10.8 & 12.0 & \\
\hline \multirow[t]{2}{*}{ Employer self-insurance } & Fully-insured & 43.8 & 54.9 & $<0.001$ & 53.5 & 52.7 & 0.533 \\
\hline & Self-insured & 56.2 & 45.1 & & 46.5 & 47.3 & \\
\hline \multirow[t]{3}{*}{ Initial Medicaid insurance } & & Non-switchers & Switchers & $p$-value & Non-switchers & Switchers & $p$-value \\
\hline & Total & 159,772 & 30,529 & & 22,294 & 22,294 & \\
\hline & Age, mean (SD) & $38.2(11.0)$ & $36.8(10.9)$ & $<0.001$ & $36.51(10.50)$ & $35.85(10.50)$ & $<0.001$ \\
\hline HCC score, mean $(\mathrm{SD})^{*}$ & & $1.50(2.39)$ & $1.18(2.06)$ & $<0.001$ & $1.20(1.99)$ & $1.24(2.13)$ & 0.04 \\
\hline \multirow[t]{2}{*}{ Sex } & Female & 62.8 & 64.8 & $<0.001$ & 64.6 & 64.7 & 0.74 \\
\hline & Male & 37.2 & 35.2 & & 35.4 & 35.3 & \\
\hline \multirow[t]{4}{*}{ Area Deprivation Index quartile ${ }^{\S}$} & 1 (least deprived) & 9.4 & 9.8 & $<0.001$ & 9.8 & 9.8 & 0.992 \\
\hline & 2 & 14.6 & 15.1 & & 15.2 & 15.3 & \\
\hline & 3 & 26.6 & 27.4 & & 27.5 & 27.5 & \\
\hline & 4 (most deprived) & 49.4 & 47.6 & & 47.5 & 47.4 & \\
\hline \multirow[t]{3}{*}{ Member ID confidence" } & Unable to assess & 1.7 & 0.3 & $<0.001$ & 0.2 & 0.3 & $<0.001$ \\
\hline & High & 19.6 & 38.2 & & 37.0 & 39.6 & \\
\hline & Moderate & 78.7 & 61.5 & & 62.9 & 60.1 & \\
\hline \multirow[t]{2}{*}{ Plan type } & Medicaid & 89.3 & 71.9 & $<0.001$ & 79.0 & 77.9 & 0.006 \\
\hline & Medicaid MCO & 10.7 & 28.1 & & 21.0 & 22.1 & \\
\hline
\end{tabular}

Abbreviations: HCC score hierarchical condition category score, SD standard deviation, ID identifier, HMO health maintenance organization, PPO preferred provider organization, POS point-of-service plan, MCO managed care organization

*Unmatched cohort includes all Massachusetts residents aged 21-64 with 3 years of continuous enrollment in private or Medicaid insurance plans covered by the APCD

${ }^{\dagger}$ Matched cohort includes all individuals switching plans between January 1, 2011, and January 1, 2013, who were able to be matched in a 1:1 ratio with another individual in the same ZIP Code tabulation area with a close propensity score match (see Methods)

${ }^{*}$ Hierarchical condition category score calculated using 2010 claims for those who switched in 2011 (or were matched to a 2011 switcher), and using 2011 claims for those who switched in 2012 or on January 1, 2013

${ }^{\S}$ The Area Deprivation Index is a weighted combination of 17 census-level indicators of socioeconomic disadvantage at the five-digit ZIP Code level, which we grouped into quartiles ${ }^{23}$

"Member ID confidence describes the qualitative fidelity of individuals' identifier linkage across the years of the APCD. See Online Appendix Methods

(see online Appendix). We assigned non-switchers the same insurance switch date as the matched switcher to align the timeline of all individuals relative to this date.

To compare the characteristics of switchers versus nonswitchers before and after matching, we used $t$-tests or $\chi^{2}$ tests as appropriate. We assessed the change in utilization of physician and ED visits using a difference-in-differences design. We defined the pre-switch period as the 12 months preceding a switch, and the post-switch period as the 12 months after a switch, including the month of the insurance change.

For the ED utilization analyses, we divided the indicator for the post-switch period by month to estimate changes in utilization over time versus the pre-switch period from 4 to 12 months before switching. We estimated linear models that included an indicator for period (pre/post or month fixed effects), an indicator for insurance switching, and interactions between the period and insurance switching indicators, which was our main quantity of interest. Even though the dynamics of insurance switching were more complex than simple pre/ post changes, we used a standard difference-in-differences framework to estimate average overall effects in the postswitch period. The model further adjusted for all available patient factors noted above (see full model specification in online Appendix). We tested for the assumption of parallel trends between switchers and non-switchers in the pre-switch period by examining whether utilization trends were equivalent between the two groups, using the same model specification as described above. All models were estimated accounting for clustering of repeated observations within individuals using generalized estimating equations. Analyses were 
performed with SAS software (version 9.4, SAS Institute Inc., Cary, NC).

\section{Sensitivity and Subgroup Analyses}

Because some insurance switching might be motivated by a change in health status or a desire to switch healthcare providers, we performed sensitivity analyses focusing on subgroups more likely to be experiencing exogenous insurance switches. First, we repeated the analyses above after restricting to individuals who were most likely to have switched due to an employer switching plans or the cancellation of an entire plan contract ("plan cancellation"). We identified these by flagging all plans or employers with 20 or more members, with at least $75 \%$ of members switching insurance on the same day, using plan identifier codes and employer tax identifiers (available for $12 \%$ of the matched sample). Second, because those who move, whether due to a job change or not, may be more likely to establish care with new providers, we restricted our analyses to those whose ZIP Code of residence did not change ( $80 \%$ of the matched sample).

In addition, because new health plans might also entail higher enrollee cost sharing that might have independent effects on post-switch utilization, we repeated our analyses on the subset of switchers for whom there was available information on insurance deductibles $(35 \%$ of the matched sample). We classified all insurance switches as those switching to a plan with a higher, equal, or lower deductible and repeated the analyses stratified by these populations.

Finally, we performed additional sensitivity analyses to replicate our analyses among patients with chronic illness, among patients with high confidence identifiers and excluding a 6-month "washout" period prior to insurance switching (methods and results in online Appendix).

\section{RESULTS}

The full study cohort included 1,628,057 individuals, of whom 418,231 , or $26 \%$, switched insurance as least once from 2011 to 2013 (see flowchart in online Appendix), with 366,327 of these switches occurring from January 1, 2011, through January 1, 2013. Of these, we matched 316,343 , or $88 \%$ of eligible switchers, to non-switchers (entire matched cohort $n=632,686$ ). Before matching, those switching insurance were younger ( 40.7 vs. 43.4 years, $p<0.001)$, less likely to have preferred provider organization (PPO) coverage ( $28.0 \%$ vs. $34.3 \%, p<0.001)$, and for the Medicaid cohort, more likely to have Medicaid managed care coverage $(28.1 \%$ vs. $10.7 \%, p<0.001)$. After matching, balance improved between switchers and non-switchers (Table 1, online Appendix). Pre-switching trends in utilization of physician and ED visits were similar ("parallel trends"), with the exception of trends in new specialist visit utilization for the initially privately insured (online Appendix). However, the divergence of these trends was small in magnitude and not persistent over time (Fig. 1b).
Figure 1 Outcome rates for insurance switchers and non-switchers by type of initial insurance. Trends in outcome rates per 100 persons for new primary care physician (PCP) visits (a), new specialist physician visits (b), and emergency department (ED) visits (c) in 30-day intervals ("months") relative to insurance switching for switchers and their matched control non-switchers. Each outcome is stratified by whether the individuals started with Medicaid or private insurance. Unadjusted rates for switchers are shown by the solid yellow/light gray line ("Switchers"). The same trend for non-switchers is shown by the solid blue/black line ("Non-switchers"). The solid vertical black line indicates the time point of insurance switching. $95 \%$ confidence intervals are shown for all unadjusted estimates, assuming a normal distribution of rates given the large sample size of individuals.

\section{New Physician Visits and Emergency Department Utilization}

Compared to non-switchers, switchers experienced a significant increase in the monthly rate of new PCP visits after insurance switching (Fig. 1a). This change was larger for those starting with Medicaid than with private coverage. In adjusted analysis, relative to non-switchers, there was an average increase of $203.4 \%(p<0.001)$ and $49.3 \%(p<0.001)$ in the monthly rate of new PCP visits for those starting with Medicaid and with private coverage, respectively (Table 2 ). These average changes were driven in part by larger short-term increases in utilization post-switching, which diminished over time (Fig. 1a). Cumulatively, in the 12-month pre- and postswitch periods, $7.0 \%$ and $17.4 \%$ of switchers initially with Medicaid coverage saw a new PCP, compared to $7.2 \%$ and $8.7 \%$ of switchers initially with private coverage.

We observed a similar pattern for new specialist visits among Medicaid patients, though less pronounced (Fig. 1b), with the adjusted rate of new specialist visits increasing by an average of $47.5 \%(p<0.001$, Table 2$)$. In contrast, there was a small decrease in the new specialist visit rate for privately insured patients after switching of 2.8\% $(p<0.001$, Table 2$)$ that resulted from a temporary decrease in the rate of new specialist visits from the month preceding an insurance switch through the month after a switch (Fig. 1b).

Among Medicaid patients, there was an increase in the rate of ED visits around the time of switching, reaching statistical significance in the month of the switch. This change represented an adjusted $14.9 \%$ increase in the rate of ED visits in the month of an insurance switch compared to the average rate in the period from 12 to 4 months prior to switching $(p<0.001$, Fig. 1c). This increase returned to the baseline rate or below in the months after switching. Among the privately insured, we observed a small statistically non-significant $(1.7 \%)$ decrease in the rate of ED visits $(p=0.16$, Table 2$)$.

\section{Sensitivity and Subgroup Analyses}

When restricting to the cohort most likely to have switched because their employer switched insurance carriers ( $n=74,030$ ), we observed a similar increase in the rate of new PCP visits ( $p<0.001$ for the post-switch period, Fig. 2a). Findings also were similar for the population who did not change ZIP codes $(n=509,038, p<0.001$ for post-switch period for both, Fig. 2b). 
A

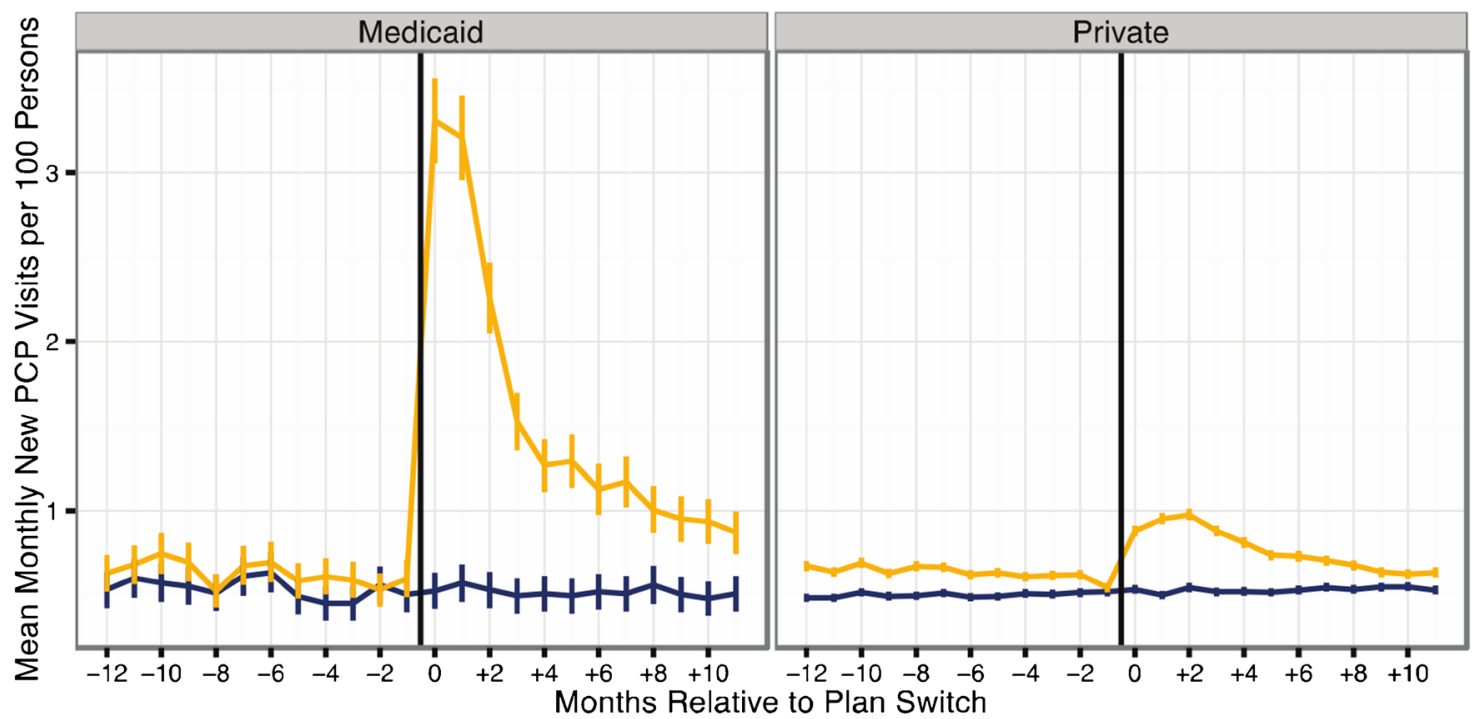

B

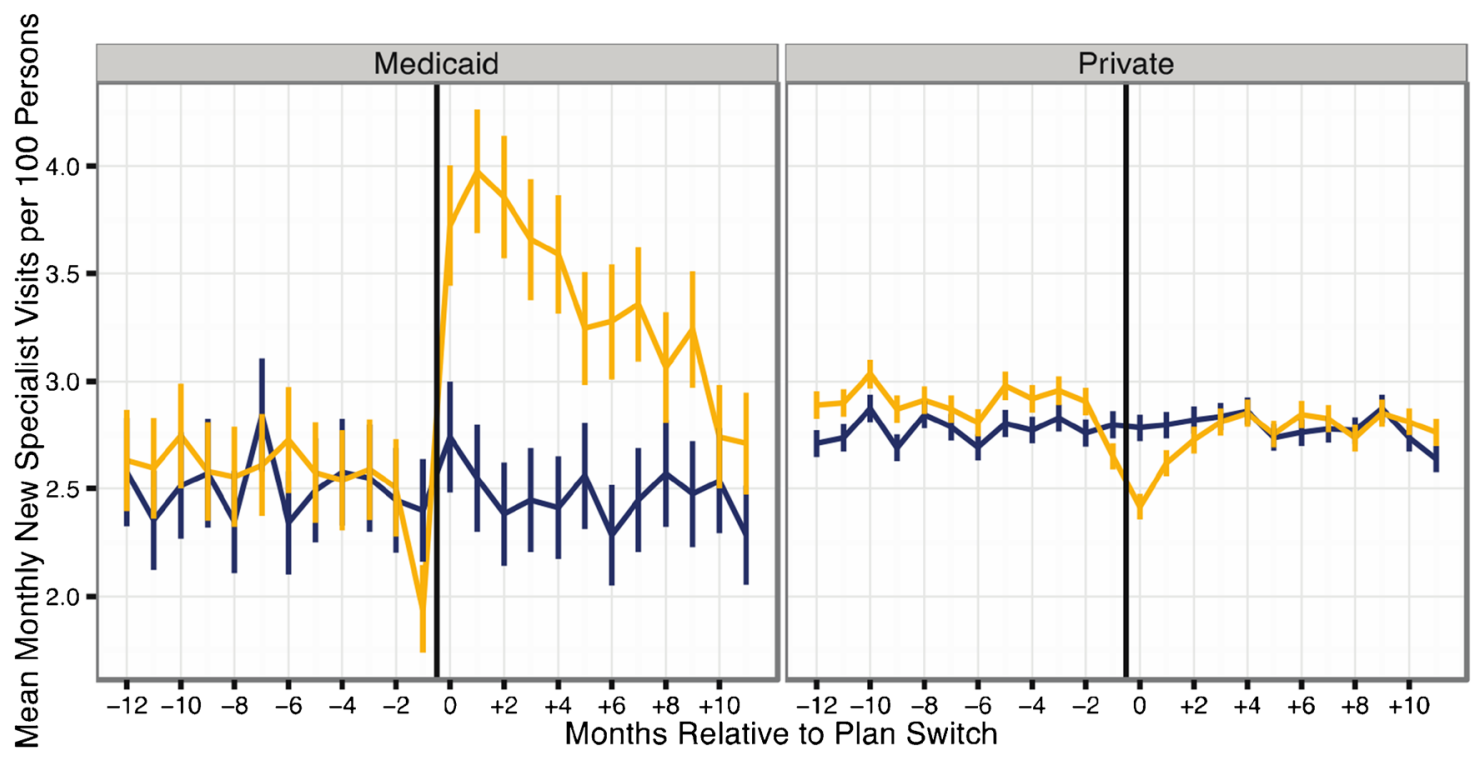

C

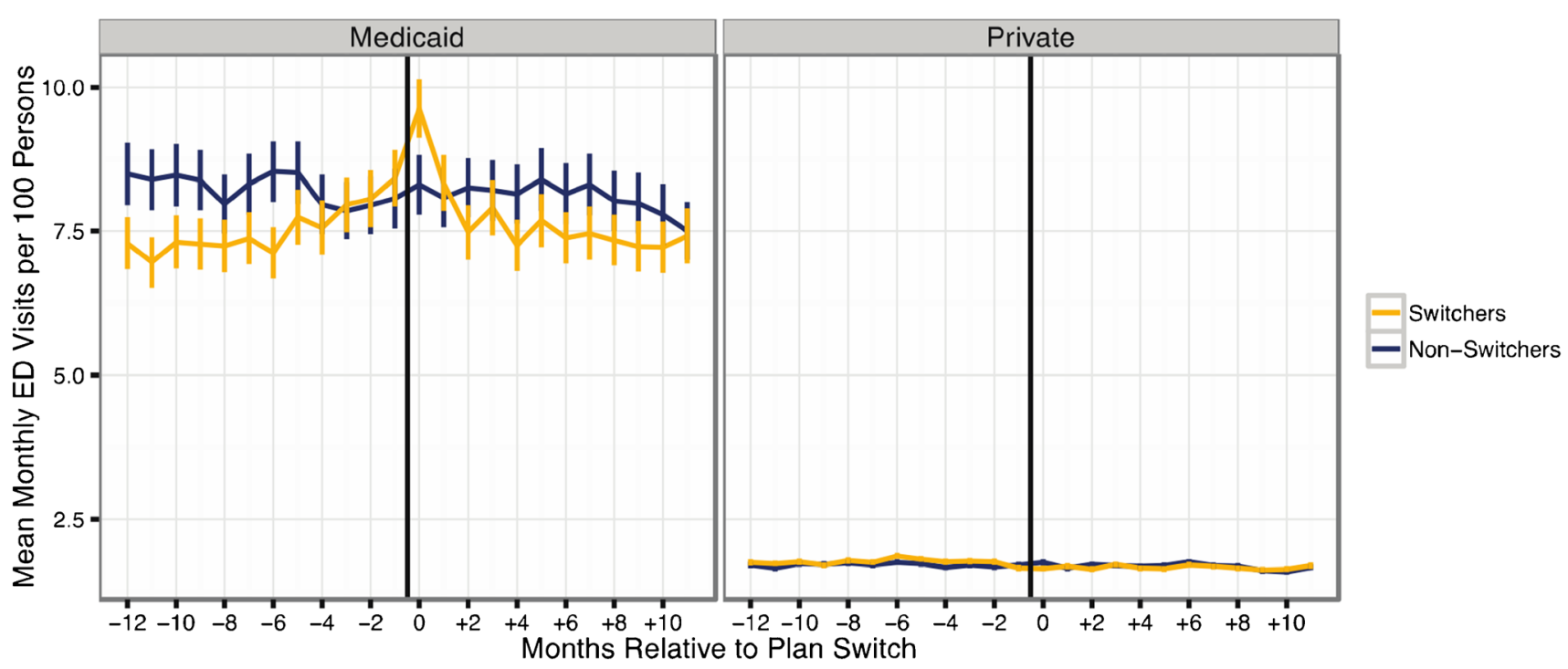


Table 2 Difference-in-Difference Estimates for Change in Utilization Attributable to Insurance Switching

\begin{tabular}{|c|c|c|c|c|c|c|c|c|c|c|}
\hline \multirow{2}{*}{$\begin{array}{l}\text { Monthly } \\
\text { utilization } \\
\text { rates per } \\
100 \text { persons }\end{array}$} & \multicolumn{3}{|c|}{ Switchers } & \multicolumn{3}{|c|}{ Non-switchers } & \multirow{2}{*}{$\begin{array}{l}\text { Raw } \\
\text { difference } \\
\text { in } \\
\text { differences* }\end{array}$} & \multirow{2}{*}{$\begin{array}{l}\text { Adjusted } \\
\text { difference } \\
\text { in } \\
\text { differences }^{\dagger}\end{array}$} & \multirow{2}{*}{$\begin{array}{l}\text { Adjusted } \\
\text { percentage } \\
\text { change } \\
\text { relative } \\
\text { to pre- } \\
\text { period }\end{array}$} & \multirow{2}{*}{$\begin{array}{l}\text { Adjusted } \\
p \text {-value }\end{array}$} \\
\hline & $\begin{array}{l}\text { Pre- } \\
\text { period }\end{array}$ & $\begin{array}{l}\text { Post- } \\
\text { period }\end{array}$ & $\begin{array}{l}\text { Percentage } \\
\text { change }\end{array}$ & $\begin{array}{l}\text { Pre- } \\
\text { period }\end{array}$ & $\begin{array}{l}\text { Post- } \\
\text { period }\end{array}$ & $\begin{array}{l}\text { Percentage } \\
\text { change }\end{array}$ & & & & \\
\hline \multicolumn{11}{|c|}{ Initial Medicaid insurance } \\
\hline $\begin{array}{l}\text { Emergency } \\
\text { department } \\
\text { visits }\end{array}$ & 7.52 & 7.69 & 2.3 & 8.24 & 8.09 & -1.8 & 0.32 & -0.48 & -6.4 & 0.02 \\
\hline $\begin{array}{l}\text { New PCP } \\
\text { visits }\end{array}$ & 0.62 & 1.58 & 152.3 & 0.53 & 0.51 & -4.1 & 0.97 & 1.27 & 203.4 & $<0.0001$ \\
\hline $\begin{array}{l}\text { New } \\
\text { specialist } \\
\text { visits }\end{array}$ & 2.55 & 3.37 & 32.2 & 2.50 & 2.47 & -1.1 & 0.85 & 1.21 & 47.5 & $<0.0001$ \\
\hline \multicolumn{11}{|c|}{$\begin{array}{l}\text { visits } \\
\text { Initial private insurance }\end{array}$} \\
\hline $\begin{array}{l}\text { Emergency } \\
\text { department } \\
\text { visits }\end{array}$ & 1.76 & 1.67 & -5.4 & 1.71 & 1.69 & -1.3 & -0.07 & -0.02 & -1.1 & 0.16 \\
\hline $\begin{array}{l}\text { New } \\
\text { PCP visits }\end{array}$ & 0.63 & 0.77 & 21.8 & 0.49 & 0.52 & 6.0 & 0.11 & 0.31 & 49.3 & $<0.0001$ \\
\hline $\begin{array}{l}\text { New } \\
\text { specialist } \\
\text { visits }\end{array}$ & 2.89 & 2.75 & -4.9 & 2.78 & 2.78 & 0.3 & -0.15 & -0.08 & -2.8 & $<0.0001$ \\
\hline
\end{tabular}

Abbreviations: $P C P$ primary care physician

* Calculated as the change from pre-period to post-period in switchers minus the same change in non-switchers, without adjustment

${ }^{\dagger}$ Estimated from a linear regression model clustering at the individual level using generalized estimating equations, adjusting for all patient characteristics shown in Table 1 (depending on initial insurance type)

${ }^{7}$ Calculated as the percentage change of the adjusted difference-in-differences estimate relative to the switcher pre-period baseline in the first column

Finally, for the subset of enrollees for whom we had information on cost sharing ( $n=126,830$ ), we found a consistent increase in the rate of new PCP visits after an insurance switch, regardless of cost-sharing changes (Fig. 3a). For new specialist visits, however, individuals moving to a plan with higher deductibles had $12.1 \%(p<0.001)$ fewer new specialist visits post-switch versus matched controls. In contrast, there was a $21.5 \%$ increase $(p<0.001)$ in new specialist visits for those moving to a plan with lower deductibles versus their matched controls (Fig. 3b).

\section{DISCUSSION}

This population-based descriptive study of insurance coverage switching in Massachusetts provides a number of potential insights about the functioning of health insurance markets. First, similar to prior research, ${ }^{4}{ }^{24}$ we found that insurance switching is common, particularly among younger individuals in managed care insurance plans. Second, we observed that insurance switching is associated with significantly higher rates of new physician visits, particularly for visits to PCPs in the months after switching. These findings were robust over our sensitivity analyses and suggest that insurance transitions among the continuously insured may be associated with physician turnover for many individuals. Whether this has negative health consequences for these individuals is not yet clear. Third, we observed an increase in ED visit rates around the time of insurance switching among the publicly insured but not among privately insured patients. Though this increase in ED visit rate was temporary, it suggests that insurance switching may be a vulnerable period, potentially reflecting individuals' uncertainty in where to seek care while coverage is in flux, though other explanations for this pattern are also possible.

An important concern for this analysis is that some insurance switching might be motivated by a desire to switch providers. In this case, increases in new physician visits could be viewed as a desired outcome rather than a negative impact of switching. Prior evidence suggests, however, that the vast majority of insurance switching is unlikely to be motivated in this way. The Community Tracking Survey found that among individuals switching private insurance, over $75 \%$ was due to employer plan cancellations or a job change, and fewer than $10 \%$ switched insurance to obtain "better services" such as preferred doctors. ${ }^{6,24,25}$ More importantly, our sensitivity analyses of alternative groups designed to exclude those with potentially endogenous motivations for switching were robust.

One likely mechanism driving the increase in new PCP visits is the lack of overlap between different insurers' provider networks. This possibility is supported by the greater turnover we see in those initially with Medicaid insurance vs. the privately insured, since the networks of physicians accepting different types of Medicaid plans in Massachusetts tend to be narrower than the networks of the large commercial insurers in the state. ${ }^{26,} 27$ These findings also have important implications for state-based exchanges, many of which rely on narrow networks and high-deductible products in order to hold down the costs 
A

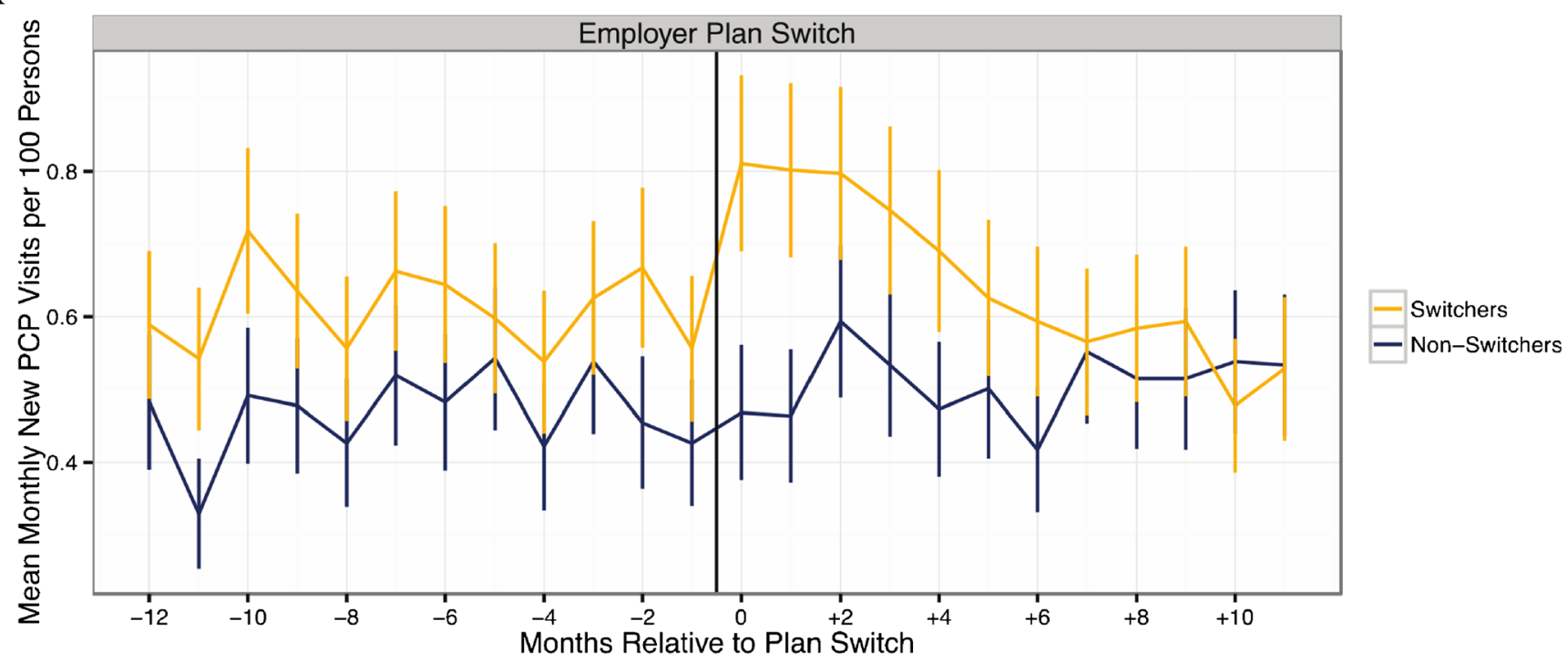

B

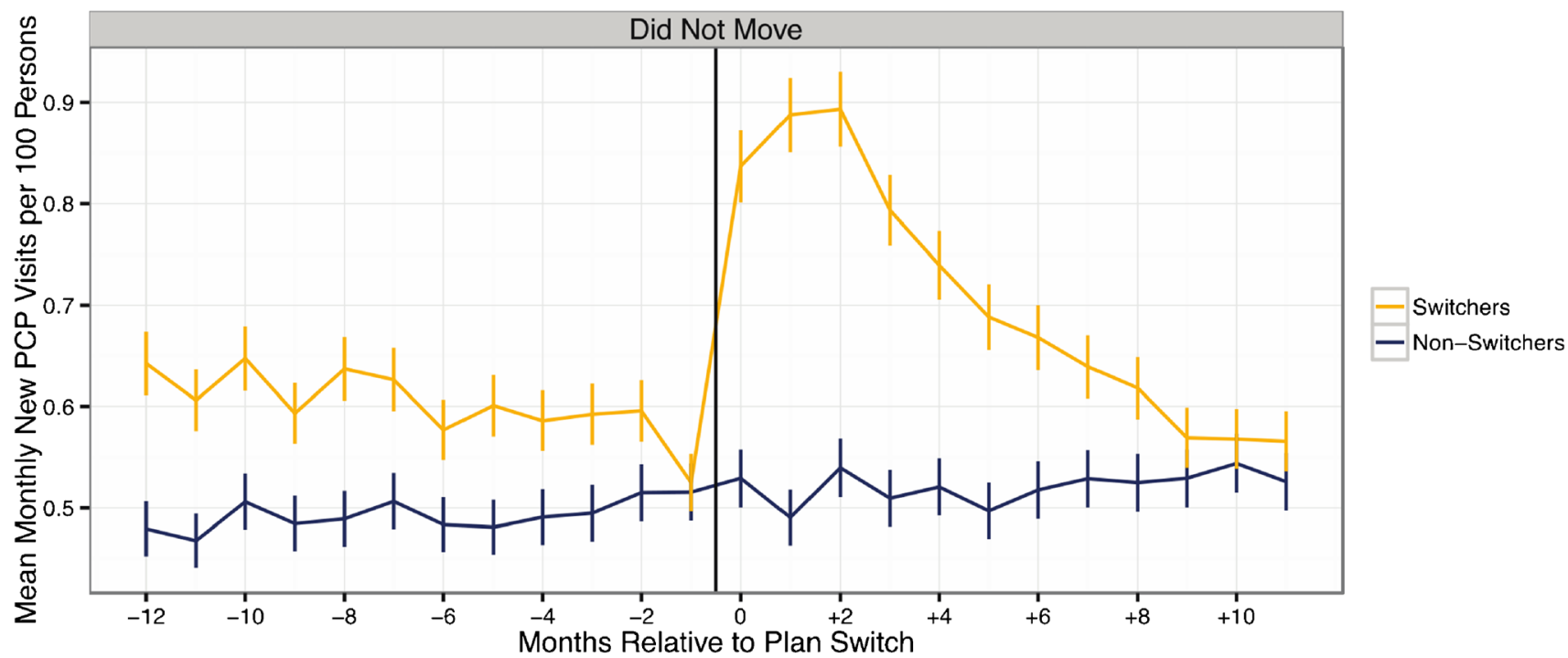

Figure 2 Changes in new PCP visit rates with insurance switching for individuals with initial private insurance coverage. Sensitivity analyses for trends in outcome rates per 100 persons for new primary care physician (PCP) visits in 30-day intervals ("months") relative to insurance switching for switchers and their matched control non-switchers. a Outcomes for the subgroup of individuals with employer insurance switches or plan cancellations ( $n=74,030$ including controls). b Outcomes for the subgroup switching insurance on January 1 or July 1 from 2011 to $2013(n=273,628$ including controls). $\mathrm{c}$ Outcomes for the subgroup of individuals living in the same ZIP Code before and after insurance switching $(n=509,038$ including controls). These analyses are restricted to individuals with initial private insurance coverage. Unadjusted rates for switchers are shown by the solid yellow/light gray line ("Switchers"). The same trend for non-switchers is shown by the blue/black solid line ("Non-switchers"). The solid vertical black line indicates the time point of insurance switching. 95\% confidence intervals are shown for all unadjusted estimates, assuming a normal distribution of rates given the large sample size of individuals.

of premiums. ${ }^{28}$ In contrast, the mixed changes in new specialist visits following insurance switching may reflect a combination of factors. Among the publicly insured who have no financial disincentive (e.g., copays) for specialty care, the increase in new specialist visits after switching may be related to the need to establish care with new specialists. In contrast, for the privately insured, individuals switching to plans with higher cost sharing appear to curb specialist use significantly, with the opposite relationship for those moving into plans with less cost sharing. ${ }^{29}$

Our results show that the combination of frequent insurance churning and the associated physician turnover may imply the presence of a fundamental tension between strongly competitive local markets and the stability of provider relationships for patients. Following from this, the success of interventions to promote continuity of care, such as accountable care organizations ${ }^{30}$ or patient-centered medical homes, ${ }^{31}$ may be sensitive to the dynamics of insurance churning in the local market. If patients are frequently switching insurance and physicians, it is difficult for delivery systems to recoup longterm investments in population health.

Our study is subject to several limitations. First, this is a descriptive, observational study and does not permit definitive 
A

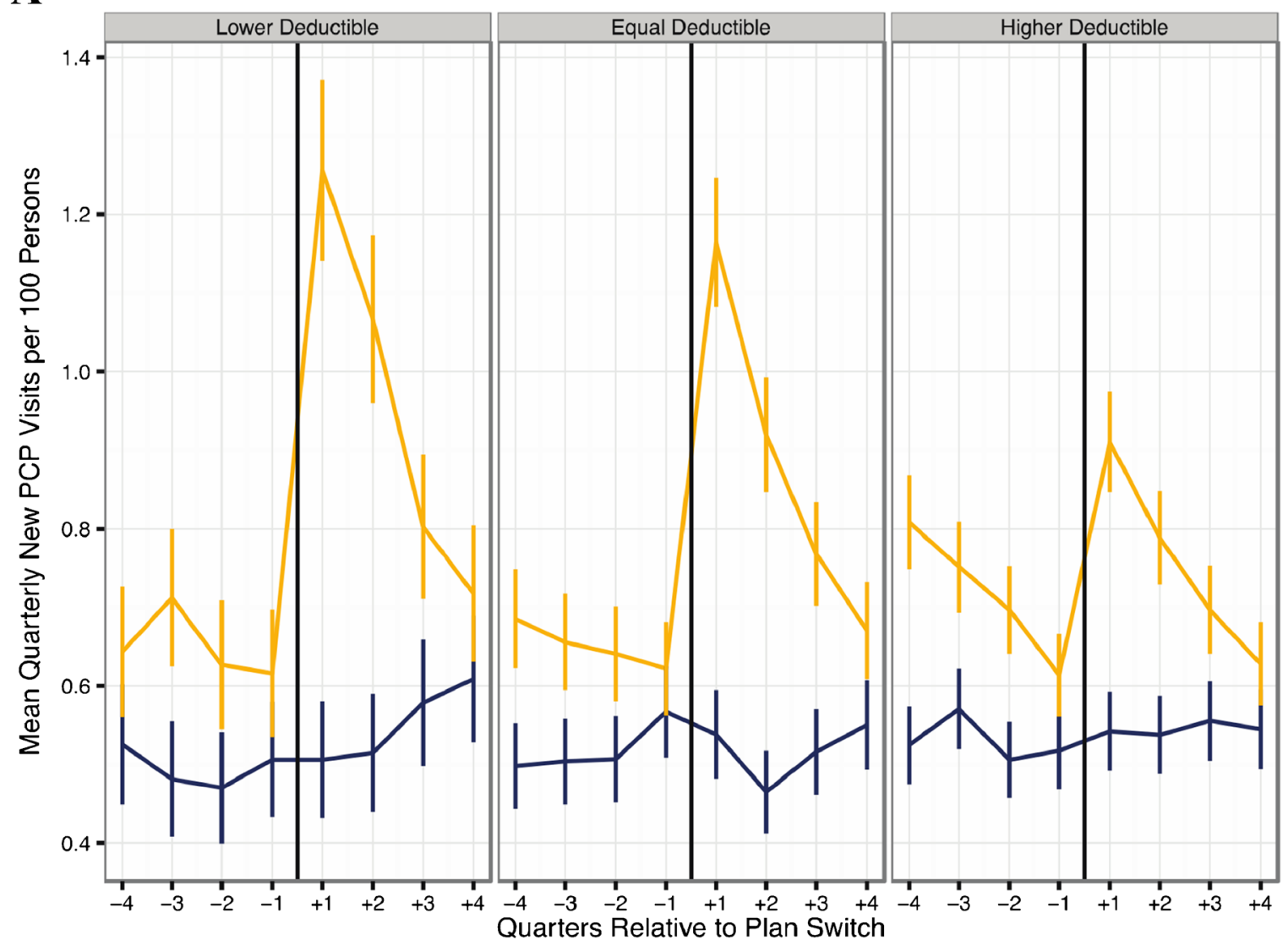

B

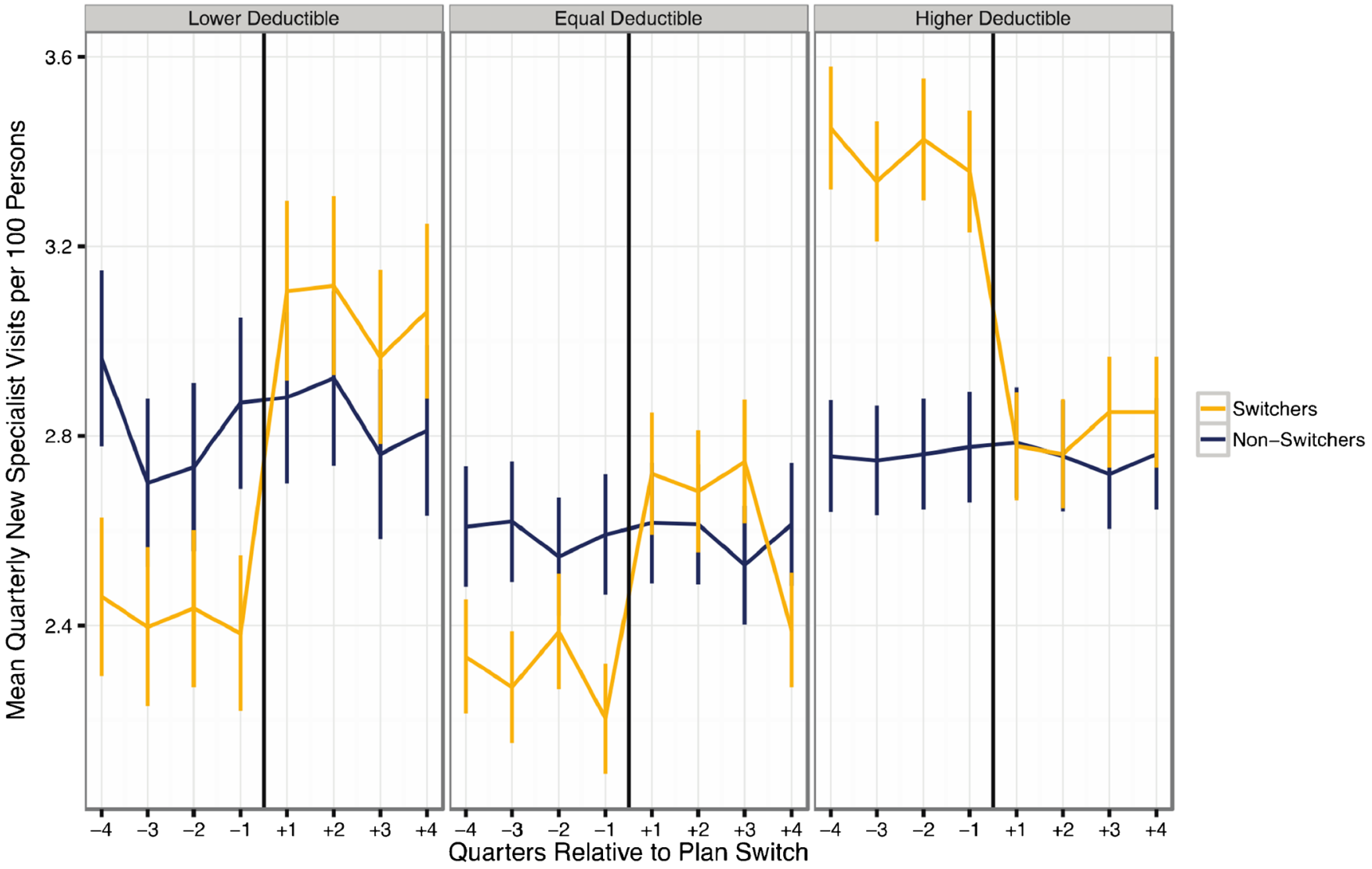


4 Figure 3 Outcome rates for individuals with initial private insurance, by change in cost sharing. Sensitivity analyses for trends in outcome rates per 100 persons for new primary care physician (PCP) visits (a) and new specialist physician visits (b) in 30-day intervals ("months") relative to insurance switching for switchers and their matched control non-switchers. Both a and b stratify these outcomes by whether individuals switched to insurance plans with a higher, equal, or lower deductible compared to their initial plan. These analyses are restricted to individuals and their matched controls with initial private insurance coverage with deductible information available before and after switching ( $n=126,830$ including controls). Unadjusted rates for switchers are shown by the solid yellow/light gray line ("Switchers"). The same trend for non-switchers is shown by the blue/black solid line ("Nonswitchers"). The solid vertical black line indicates the time point of insurance switching. 95\% confidence intervals are shown for all unadjusted estimates, assuming a normal distribution of rates given the large sample size of individuals.

causal conclusions to be drawn about the impact of insurance switching on utilization. We use a matched group of nonswitchers to confirm that our findings were not driven by secular trends, but our sensitivity analyses could not address all potential sources of confounding bias. For example, we are unable to assess the role of disability status or income fluctuations in the dynamics of the switcher and non-switcher populations with Medicaid coverage. Second, we focus on a continuously insured population in Massachusetts, which may not necessarily reflect the dynamics of insurance markets nationally. Third, given the limited time window for this study, we are unable to fully characterize patients' prior physician relationships, which can span many years. We rely instead on a conservative measure of physician switching defined by "new visit" CPT codes, which potentially underestimates the impact of insurance switching. Fourth, as seen in the patterns of utilization changes for the Medicaid-covered population, there were important anticipatory changes in utilization preceding switching that biased the estimates of our dichotomous pre/ post model specification. Our sensitivity analysis excluding a prior "washout period" showed that most of our results were robust to this exclusion, though our findings for ED visits in the Medicaid population became non-significant, reflecting that this utilization pattern diverged from a simple pre/post change. Finally, we only examined switches across insurance carriers, rather than across plans with different design elements within insurers. To the extent that some switches within a carrier represented switches to either tiered or narrow network plans, our results may further underestimate potential changes due to insurance switching.

In conclusion, we found that insurance switching is common, and is associated with increased physician turnover and temporarily increased ED use among the publicly insured. These findings suggest that insurance churning may be a medically vulnerable and clinically relevant period, particularly for the publicly insured. Whether the possibly negative consequences exceed the benefits of switching for some enrollees will be an important question for consumers, payers, and policymakers going forward in this era of evolving health care policy reform.
Acknowledgements: This work is supported by grants from the National Institute for Health Care Management and HRSA (T32HP10251). The contents of this publication are solely the responsibility of the authors and do not represent the official views of HRSA, CMMI, or CMS.

This work was presented in part at the AcademyHealth Annual Research Meeting in June 2015 (Minneapolis, MN).

Corresponding Author: Bruce E. Landon, MD, MBA, MSc; Department of Health Care PolicyHarvard Medical School, 180A Longwood Ave, Boston, MA 02115, USA (e-mail: landon@hcp.med.harvard.edu).

\section{Compliance with Ethical Standards:}

Conflict of Interest: $A B$ is a senior advisor at the Center for Medicare and Medicaid Innovation (CMMI), working on the Comprehensive Primary Care Plus (CPC+) initiative. All other authors declare that they do not have a conflict of interest.

\section{REFERENCES}

1. Kaiser Family Foundation. Summary of the Affordable Care Act. http:// kff.org/health-reform/fact-sheet/summary-of-the-affordable-care-act/. Accessed April 12, 2017.

2. Cutler DM, Gelber AM. Changes in the Incidence and Duration of Periods without Insurance. N Engl J Med 2009;360(17):1740-1748. doi:10.1056/NEJMsa0804668.

3. Sommers BD, Rosenbaum S. Issues In Health Reform: How Changes In Eligibility May Move Millions Back And Forth Between Medicaid And Insurance Exchanges. Health Aff 2011;30(2):228-236. doi:10.1377/ hlthaff.2010.1000.

4. Sommers BD. Insurance Cancellations In Context: Stability Of Coverage In The Nongroup Market Prior To Health Reform. Health Aff 2014;33(5):887-894. doi:10.1377/hlthaff.2014.0005.

5. Graves JA, Swartz K. Understanding State Variation In Health Insurance Dynamics Can Help Tailor Enrollment Strategies For ACA Expansion. Health Aff 2013;32(10):1832-1840. doi:10.1377/hlthaff.2013.0327.

6. Cunningham PJ, Kohn L. Health plan switching: choice or circumstance? Health Aff 2000;19(3):158-164. doi:10.1377/hlthaff.19.3. 158.

7. Atherly A, Florence C, Thorpe KE. Health Plan Switching among Members of the Federal Employees Health Benefits Program. Inquiry 2005;42(3):255-265. doi:10.5034/inquiryjrnl_42.3.255.

8. Insurers and States Aim to Ensure Medicaid Coverage Continuity Between Medicaid and Private Plans. Modern Healthcare. http://www. modernhealthcare.com/article/20140726/MAGAZINE/307269980?mh. Accessed April 12, 2017.

9. Chernew ME, Wodchis WP, Scanlon DP, McLaughlin CG. Overlap In HMO Physician Networks. Health Aff 2004;23(2):91-101. doi:10.1377/ hlthaff.23.2.91.

10. Burstin HR, Swartz K, O'Neil AC, Orav EJ, Brennan TA. The effect of change of health insurance on access to care. Inquiry 1998:389-397.

11. Lavarreda SA, Gatchell M, Ponce N, Brown ER, Chia YJ. Switching Health Insurance and Its Effects on Access to Physician Services: Med Care. 2008;46(10): 1055-1063. doi:10.1097/MLR.0b013e318187d8db.

12. Hospital networks: Updated national view of configurations on the exchanges | McKinsey on Healthcare. http://healthcare.mckinsey.com/ hospital-networks-updated-national-view-configurations-exchanges. Accessed April 12, 2017.

13. Swartz K, McBride TD. Spells Without Health Insurance: Distributions of Durations and Their Link to Point-in-Time Estimates of the Uninsured. Inquiry 1990;27(3):281-288.

14. Center for Health, Information and Analysis. Massachusetts Health Insurance and Employer Survey Chartbook: Updates for 2011. 2013. http://chiamass.gov/assets/docs/r/pubs/13/mhischartpack-1-29-13. pdf. Accessed April 12, 2017.

15. Center for Health Information and Analysis. Overview of the Massachusetts All-Payer Claims Database. 2014. http://chiamass.gov/assets/ docs/p/apcd/apcd-overview-2014.pdf. Accessed April 12, 2017.

16. Center for Health. Monthly APCD User Workgroup Webinar. 2014. http://www.chiamass.gov/assets/docs/p/apcd/workgroup-meetings / 2014-04-22-apcd-user-group-presentation.pdf. Accessed April 12, 2017. 
17. CMS: FAQs. https://questions.cms.gov/faq.php?id=5005\&faqId=1969 Accessed April 12, 2017.

18. MaCurdy, T, J Bhattacharya, D Perlroth, et al. Geographic Variation in Spending, Utilization and Quality: Medicare and Medicaid Beneficiaries. 2013. http://www.nationalacademies.org/hmd/ /media/Files / Report\%20Files/2013/Geographic-Variation/Sub-Contractor/AcumenMedicare-Medicaid.pdf. Accessed April 12, 2017.

19. Joynt KE, Chan DC, Zheng J, Orav EJ, Jha AK. The Impact of Massachusetts Health Care Reform on Access, Quality, and Costs of Care for the Already-Insured. Health Serv Res 2014:599-613. doi:10. 1111/1475-6773.12228.

20. Pope, GC, Kautter, J, Ingber, MJ, Freeman, S, Sekar, R, Newhart, C. Evaluation of the CMS-HCC Risk Adjustment Model. 2013. https://www.cms.gov/Medicare/Health-Plans/MedicareAdvtgSpecRateStats/Downloads/Evaluation_Risk_Adj_Model_2011.pdf. Accessed April 12, 2017.

21. Singh GK. Area Deprivation and Widening Inequalities in US Mortality, 1969-1998. Am J Public Health 2003;93(7):1137-1143. doi:10.2105/ AJPH.93.7.1137.

22. Kind AJH, Jencks S, Brock J, et al. Neighborhood Socioeconomic Disadvantage and 30-Day Rehospitalization. Ann Intern Med 2014;161(11):765-774. doi:10.7326/M13-2946.

23. Area Deprivation Index. HIPxChange.org. http://www.hipxchange.org/ ADI. Published November 13, 2013. Accessed April 12, 2017.
24. Cebul RD, Rebitzer JB, Taylor LJ, Votruba ME. Unhealthy Insurance Markets: Search Frictions and the Cost and Quality of Health Insurance. Am Econ Rev 2011;101(5):1842-1871. doi:10.1257/aer.101.5.1842.

25. NIHCR: Few Americans Switch Employer Health Plans for Better Quality, Lower Costs. http://nihcr.org/analysis/improving-care-delivery/prevention-improving-health/health-plan-switching/. Accessed April 12, 2017.

26. Network Adequacy in Medicaid Managed Care: Recommendations for Advocates. http://www.healthlaw.org/issues/medicaid/network-adequacy-in-medicaid-managed-care\#.VtWVDIwrKAE. Accessed April 12, 2017.

27. Priyanka Dayal McCluskey. New policy for Children's affects poorest patients - The Boston Globe. BostonGlobe.com. https://www.bostonglobe.com/business/2016/04/06/childrens/LwqEe2w5jQx8zL1xuS2JUI/story.html. Accessed April 12, 2017.

28. Summer L. Health Plan Features: Implications of Narrow Networks and the Trade-Off between Price and Choice. 2014. http://www.academyhealth.org/publications/2015-03/health-plan-features-implicationsnarrow-networks-and-trade-between-price-and. Accessed April 12, 2017.

29. Newhouse JP, Group, IE. Free for All? http://www.rand.org/pubs/ commercial_books/CB199.html. Published 1993. Accessed April 12, 2017.

30. Luft HS. Becoming Accountable-Opportunities and Obstacles for ACOs. N Engl J Med 2010;363(15):1389-1391. doi:10.1056/NEJMp1009380.

31. Rittenhouse DR, Shortell SM, Fisher ES. Primary Care and Accountable Care-Two Essential Elements of Delivery-System Reform. N Engl J Med 2009;361(24):2301-2303. doi:10.1056/NEJMp0909327. 